\title{
Growth performance, in vitro antioxidant properties and chemical composition of the halophyte Limonium algarvense Erben are strongly influenced by the irrigation salinity
}

\author{
Maria João Rodrigues ${ }^{\mathrm{a}}$, Ivo Monteiro ${ }^{\mathrm{b}}$, Viana Castañeda-Loaiza ${ }^{\mathrm{a}}$, Chloé Placines ${ }^{\mathrm{a}}$, \\ M. Conceição Oliveira ${ }^{\mathrm{c}}$, Catarina Reis ${ }^{\mathrm{d}}$, Ana D. Caperta ${ }^{\mathrm{e}}$, Florbela Soares ${ }^{\mathrm{b}}$, \\ Pedro Pousão-Ferreira ${ }^{\mathrm{b}}$, Catarina Pereira ${ }^{\mathrm{a}}$, Luísa Custódio ${ }^{\mathrm{a}, *}$ \\ ${ }^{a}$ Centre of Marine Sciences, University of Algarve, Faculty of Sciences and Technology, Ed. 7, Campus of Gambelas, 8005-139 Faro, Portugal \\ b IPMA, Aquaculture Research Station, Olhão, Portugal \\ ${ }^{\mathrm{c}}$ Centro de Química Estrutural, Complexo Interdisciplinar, Instituto Superior Técnico, ULisboa, Av. Rovisco Pais, 1049-001 Lisboa, Portugal \\ ${ }^{\mathrm{d}}$ Faculdade de Farmácia, Universidade de Lisboa, Av. Prof. Gama Pinto, 1649-003 Lisboa, Portugal \\ ${ }^{\mathrm{e}}$ Linking Landscape, Environment, Agriculture and Food (LEAF), Instituto Superior de Agronomia (ISA), Universidade de Lisboa, Tapada da Ajuda, Lisboa, Portugal
}

\section{A R T I C L E I N F O}

\section{Keywords:}

Aquaculture wastewater

Dietary supplements

Halophyte cultivation

Phenolic compounds

Sea lavender

\begin{abstract}
A B S T R A C T
Limonium algarvense Erben (sea lavender) is a halophyte species with potential to provide natural ingredients with in vitro antioxidant, anti-inflammatory, neuroprotective and antidiabetic properties. This study reports for the first time the 1) cultivation of sea lavender in greenhouse conditions under irrigation with freshwater (approx. $0 \mathrm{mM} \mathrm{NaCl}$ ) and saline aquaculture wastewater (300 and $600 \mathrm{mM} \mathrm{NaCl}$ ), and 2) the influence of the irrigation salinity on the plant performance (e.g. growth, number of produced leaves and flowers), in vitro antioxidant properties [radical scavenging activity (DPPH and ABTS), ferric reducing antioxidant power (FRAP), metal chelating properties on copper (CCA) and iron (ICA)], toxicity (in vitro on three mammalian cell lines) and chemical composition (determined by LC-ESI-HRMS/MS). The freshwater-irrigated plants had better growth performance than those irrigated with saltwater. Extracts from wild plants, had the highest antioxidant activity, but those from cultivated ones kept high in vitro antioxidant properties and interesting chemical profile. The flowers' extracts of plants irrigated with $300 \mathrm{mM} \mathrm{NaCl}$ had the highest antioxidant activities against DPPH, whereas those from freshwater-irrigated plants were more active on ABTS, CCA and FRAP. Most of the extracts showed nil toxicity. The flowers' extracts displayed the highest diversity of compounds, mainly quercetin, apigenin, luteolin, naringenin and their glycoside derivatives. Moreover, their abundance varied with the irrigation salinity. These data indicate that sea lavender plants can be successfully cultivated in greenhouse conditions under fresh- and saltwater irrigation, maintaining interesting biological and chemical properties.
\end{abstract}

\section{Introduction}

Plants are used as a source of health improvement commodities since ancient times, generally as herbal infusions, juices, elixirs, and extracts (Miroddi et al., 2013). Nowadays, botanical nutraceuticals (e.g. raspberry ketones, green tea supplements, echinacea, Garcinia cambogia, Ginkgo biloba) are also used with the same purposes: to improve health, delay the aging process, prevent chronic diseases, increase life expectancy, and support the structure or function of the body (Nicoletti, 2012; Nasri et al., 2014). These products are sold in different forms, like fresh or dried products, liquid or solid extracts, tablets, capsules, powders, or tea bags (Grand View Research, 2017). Products containing natural ingredients, such as nutraceuticals, have generally easier access to consumers, lower prices and are more effective when compared to prescription drugs, which combined with the growing consumer awareness of the importance of a healthier lifestyle increased the popularity of these products and the demand for natural-based formulations (Nasri et al., 2014; Grand View Research, 2017). This boosted the need to identify and develop innovative and bioactive nutraceutical ingredients, sustaining the projections for the global nutraceuticals market of 578 billion dollars by 2025 (Grand View Research, 2017).

Halophytes are salt-tolerant plants able to grow and prosper under

\footnotetext{
* Corresponding author.

E-mail address: lcustodio@ualg.pt (L. Custódio).
} 
several abiotic stressors, such as high salinity, high UV radiation and drought (Koyro and Huchzermeyer, 2004; Flowers and Colmer, 2008). This is possible due to different physiological and biochemical adaptations, including the production of potent antioxidant molecules, as for example phenolic acids and flavonoids (Ksouri et al., 2012). Besides their vital role in plant protection against oxidative stress, these molecules display important health improving properties (e.g. antioxidant, and anti-inflammatory), and are therefore of high interest for different commercial areas (e.g. food, pharmaceutical and cosmetics; Flowers et al., 2010; Ksouri et al., 2012; Panche et al., 2016). Halophytes are therefore considered an important pool of natural bioactive ingredients with high added value for several applications, namely as nutraceuticals and dietary supplements (Ksouri et al., 2012). Some species are already commercially exploited for different purposes, as for example Hippophae rhamnoides L. (sea buckthorn) as a source of food supplement and cosmetic ingredient (Biotona, 2019; Pipingrock, 2019), Chenopodium quinoa Willd. (quinoa) and Salicornia spp. (sea asparagus) as food (QuinoaPortuguesa, 2019; Riafresh, 2019) and Chrithmum maritimum L. (sea fennel), as a source of cosmetic ingredient (Phytomer, 2019; Seppic, 2019).

The commercial exploitation of a plants must rely on its sustainable cultivation. Halophytes can grow in saline conditions where conventional crops (glycophytes) cannot, such as in integrated multi-trophic aquaculture (IMTA) systems where saline aquaculture effluents are used as irrigation and fertilizers for plant production (Ventura et al., 2015; Waller et al., 2015; Custódio et al., 2017). IMTAs are recommended to accomplish environmental sustainability by biomitigation of aquaculture wastes, while allowing for potential additional incomes by adding crops for commercial purposes, either as food or as sources of bioactive ingredients (Troell et al., 2009). In Europe, the cultivation of some halophytes in IMTA systems was already addressed, including Aster tripolium L. (sea aster) and different Salicornia species (sea asparagus) (Buhmann et al., 2015; Waller et al., 2015; Custódio et al., 2017).

In our ongoing studies for the commercial valorisation of southwest Portugal selected halophytes, we have identified the endemic species $L$. algarvense Erben (sea lavender) as a potential source of natural ingredients with in vitro antioxidant, anti-inflammatory, neuroprotective and antidiabetic properties (Rodrigues et al., 2015, 2016, 2019a). If commercial exploitation of this species is to be attempted, one must guarantee its sustainable cultivation and the production of biomass with desired properties. Therefore, this work had three main goals: 1) determine if sea lavender plants can be successfully cultivated in greenhouse conditions; 2) determine the influence of irrigation salinity on plant performance, chemical composition and in vitro antioxidants properties of produced sea lavender plants, and 3) evaluate if cultivated plants retain the in vitro antioxidant properties and chemical components of wild plants. For that purpose, sea lavender seeds were collected from the wild and germinated for three weeks, under freshwater irrigation. Obtained plants were then cultivated in greenhouse conditions and irrigated with freshwater (approximately $0 \mathrm{mM} \mathrm{NaCl}$ ) and aquaculture wastewater in two different dilutions: whole water $(600 \mathrm{mM}$ $\mathrm{NaCl})$ and 1:1 dilution (300 $\mathrm{mM} \mathrm{NaCl})$. Produced plants were divided into leaves, peduncles and flowers which were used to prepare ethanol extracts by an ultrasound-assisted extraction. Extracts were evaluated for in vitro antioxidant (radical scavenging and metal chelating) and toxicological properties followed by a chemical characterization of the extracts by liquid chromatography (LC) tandem high-resolution mass spectrometry (HRMS) analysis. Results were compared with those obtained with biomass from sea lavender collected from the wild.

\section{Materials and methods}

\subsection{Chemicals}

Folin-Ciocalteau (F-C) phenol reagent and all solvents used for chemical analysis were bought from Merck (Germany), while SigmaAldrich (Germany) provided the 1,1-diphenyl-2-picrylhydrazyl (DPPH), 2,2'-azino-bis(3-ethylbenzothiazoline-6-sulphonic acid) (ABTS) and butylated hydroxytoluene (BHT). Further chemicals and solvents were supplied by VWR International (Belgium). Methanol, acetonitrile, water LC-MS optima grade, and formic acid LC-MS grade were supplied by Fisher Scientific (Hampton, USA).

\subsection{Plant material}

Sea lavender wild plants were collected in the South of Portugal (Ria de Alvor) in June of 2018 (coordinates: $\left.37^{\circ} 07^{\prime} 34.8^{\prime \prime} \mathrm{N} 8^{\circ} 35^{\prime} 54.9^{\prime \prime} \mathrm{W}\right)$. The taxonomical classification was performed by the botanist Dr Manuel J. Pinto (National Museum of Natural History, University of Lisbon, Botanical Garden, Portugal) and a voucher specimen is kept in the herbarium of the XtremeBio laboratory (voucher code XBH1.2). The plants were separated into flowers, peduncles and leaves, dried for 3 days at $40{ }^{\circ} \mathrm{C}$, powdered and stored at $-20^{\circ} \mathrm{C}$ until needed. Seeds from sea lavender were collected in the southern Portugal (Ria de Alvor; coordinates: $\left.37^{\circ} 07^{\prime} 34.8^{\prime \prime} \mathrm{N} 8^{\circ} 35^{\prime} 54.9^{\prime \prime} \mathrm{W}\right)$.

\subsection{Greenhouse cultivation}

\subsubsection{Germination}

Germination was made in polystyrene plant trays (1 seed per each $3 \times 3 \mathrm{~cm}$ alveoli, 54 seeds in total), in a 3:1 mixture of peat and perlite (v/v). Seeds were moistened every two days with freshwater (approximately $0 \mathrm{mM} \mathrm{NaCl}$ ), and germination percentage was recorded weekly, for 3 weeks. Germination was carried out in plastic-greenhouse conditions with a relative humidity of $20-80.2 \%(\mathrm{~min} / \mathrm{max})$ and average temperatures of $7-33.5^{\circ} \mathrm{C}(\min / \max$.$) .$

\subsubsection{Plant production}

Eight weeks after seeding, plantlets were transplanted to $1 \mathrm{~L}$ pots (15 per treatment), containing the same substrate mixture used for germination (3:1 mixture of peat and perlite, v/v), and were irrigated with freshwater during an adaptation period of 4 weeks. Then, plants were irrigated with progressively increasing concentrations of sterilized saline aquaculture wastewater [from an outdoor tank producing Sparus aurata L. (sea bream) and Dicentrarchus labrax L. (sea bass)], starting from approximately $50 \mathrm{mM}$ with an increase of $50 \mathrm{mM}$ every two days up to the final concentration. Plants were watered every two days with $100 \mathrm{~mL}$ of the irrigation solutions with different $\mathrm{NaCl}$ levels, namely approximately 0 (freshwater), $600 \mathrm{mM} \mathrm{NaCl}$ (whole water) and $300 \mathrm{mM} \mathrm{NaCl}$ (1:1 dilution with freshwater), in each alveolus. The main nutritional components of the used wastewater are summarized in Table S1 of the Supplementary material. Once a week the freshwater irrigation solution was supplemented with liquid fertilizer (NPK 7-5-6). The photoperiod varied among $13 / 11$ and $14 / 10 \mathrm{~h}$ (day/night) for 1-7 and 8-14 weeks, respectively. The greenhouse temperature and relative humidity conditions, during the 14 weeks of the treatments, are presented in Fig. S1 of Supplementary material.

\subsubsection{Evaluation of growing parameters, fresh (FW) and dry (DW) weights and moisture}

After 14 weeks of saline irrigation, the number and height of floral stems were measured, and the leaf number was determined. The plants were then collected and separated into flowers, peduncles and leaves. The leaf surface area was determined (3 leaves per treatment), together with the FW and DW of aerial parts. Moisture was calculated as the difference between FW and DW. Plant survival was also determined. Samples from identical conditions were pooled in a single sample, freeze-dried, powdered and stored at $-20^{\circ} \mathrm{C}$. 


\subsection{Metabolomics and in vitro antioxidant properties}

\subsubsection{Preparation of the extracts}

Dried biomass (cultivated and from the wild) was extracted with ethanol by an ultrasound-assisted extraction procedure $(1: 40, \mathrm{w} / \mathrm{v})$ for $30 \mathrm{~min}$. The extracts were filtered (Whatman $\mathrm{n}^{\mathrm{o}} 4$ ), evaporated under reduced pressure and temperature in a rotary evaporator, weighted, dissolved at the concentration of $10 \mathrm{mg} / \mathrm{mL}$ in ethanol, and stored at $-20{ }^{\circ} \mathrm{C}$.

2.4.2. Chemical profile of the extracts by liquid chromatography-tandem high-resolution mass spectrometry (LC-HRMS/MS) analysis

The sea lavender extracts were analysed by Liquid Chromatography (UHPLC Elute) interfaced with a QqTOF Impact II mass spectrometer equipped with an ESI source (Bruker Daltonics). Chromatographic separation was carried out on a C18 reversed-phase Halo column $100 \AA$ $(150 \mathrm{~mm} \times 2.1 \mathrm{~mm}, \quad 2.7 \mu \mathrm{m}$ particle size; Advanced Materials Tecnology). Mobile phase consisted in water containing $0.1 \%$ formic acid (A) and acetonitrile containing $0.1 \%$ formic acid (B). The used elution gradient (A:B, v/v) was as follows: $95: 5$ from 0 to $2.5 \mathrm{~min}$; $5: 100 \mathrm{~min}$ at 24.5 to $28 \mathrm{~min} ; 95: 5$ at 30 to $36 \mathrm{~min}$. The injected volume was $8 \mu \mathrm{L}$, the flow rate was $300 \mu \mathrm{L} / \mathrm{min}$, and the temperature of the column and autosampler were maintained at $40{ }^{\circ} \mathrm{C}$ and $8{ }^{\circ} \mathrm{C}$, respectively.

The high resolution mass spectra were acquired in the ESI negative mode, the optimized parameters were set as follows: ion spray voltage, $-2.5 \mathrm{kV}$; end plate offset, $500 \mathrm{~V}$, nebulizer gas $\left(\mathrm{N}_{2}\right), 2.8$ bars; dry gas $\left(\mathrm{N}_{2}\right), 8 \mathrm{Lmin}^{-1}$; dry heater, $200^{\circ} \mathrm{C}$. Internal calibration was performed on the high-precision calibration mode (HPC) with a solution of sodium formate $10 \mathrm{mM}$ introduced to the ion source via a $20 \mu \mathrm{L}$ loop at the beginning of each analysis using a six-port valve. Acquisition was performed in full scan mode in the $m / z$ 100-1000 range, and in a datadepending MS/MS mode, with an acquisition of $5 \mathrm{~Hz}$ using a fixed cycle time of $2 \mathrm{~s}$, a dynamic exclusion duration of $0.5 \mathrm{~min}$. and a $\mathrm{m} / \mathrm{z}$-dependent isolation window of $0.03 \mathrm{Da}$. Data acquisition and processing were performed using DataAnalysis 4.2 software (Bruker Daltoniks).

\subsubsection{Radical scavenging activity (RSA) on $D P P H^{-}$and $A B T S^{+}$}

Samples were tested for RSA against the DPPH and ABTS radicals at concentrations ranging from 10 to $1000 \mu \mathrm{g} / \mathrm{mL}$, as described previously (Rodrigues et al., 2015). BHT was used as a positive control at the same concentrations of the samples. Results were expressed as a percentage of inhibition, relative to a control containing ethanol in place of the sample, and as half-maximal inhibitory concentration ( $\mathrm{IC}_{50}$ values, $\mu \mathrm{g}$ / $\mathrm{mL})$, when possible.

\subsubsection{Ferric reducing antioxidant power (FRAP)}

The ability of the extracts to reduce $\mathrm{Fe}^{3+}$ was assayed by the method described by Rodrigues et al. (2015). Absorbance was measured at $700 \mathrm{~nm}$ (Biotek Synergy 4), and increased absorbance of the reaction mixture indicated increased reducing power. Results were expressed as a percentage relative to the positive control (BHT, $1 \mathrm{mg}$ / $\mathrm{mL})$, and as $\mathrm{IC}_{50}$ values $(\mu \mathrm{g} / \mathrm{mL})$, when possible.

\subsubsection{Metal chelating activity on iron (ICA) and copper (CCA)}

ICA and CCA were tested on samples at different concentrations $(10-1000 \mu \mathrm{g} / \mathrm{mL}$ ) as described previously (Rodrigues et al., 2015). The change in colour was measured on a microplate reader (Biotek Synergy 4). EDTA was used as the positive control at the same concentrations of the samples. Results were expressed as a percentage of inhibition, relative to a control containing ultrapure water in place of the sample, and as $\mathrm{IC}_{50}$ values $(\mu \mathrm{g} / \mathrm{mL})$, whenever possible.

\subsection{Cell culture and cytotoxicity of the extracts}

The murine RAW 264.7 macrophages, the human embryonic kidney
(HEK) 293, and the human hepatocellular carcinoma HepG2 cell lines were respectively provided by the Faculty of Pharmacy and Centre for Neurosciences and Cell Biology (University of Coimbra, Portugal), the Functional Biochemistry and Proteomics, and the Marine Molecular Bioengineering groups (Centre of Marine Sciences, Portugal).

The RAW 264.7 cells were maintained in RPMI 1640 culture media, while HEK 293 and HepG2 cell lines were cultured in DMEM media, both supplemented with $10 \%$ heat-inactivated FBS, $1 \%$ L-glutamine $(2 \mathrm{mM})$, and $1 \%$ penicillin $(50 \mathrm{U} / \mathrm{mL}) /$ streptomycin $(50 \mu \mathrm{g} / \mathrm{mL})$. All cell lines were kept at $37^{\circ} \mathrm{C}$ in a moistened atmosphere with $5 \% \mathrm{CO}_{2}$. Exponentially growing cells were plated in 96-well tissue plates at a density of $1 \times 10^{4}$ cells/well (RAW 264.7) and $5 \times 10^{3}$ cells/well (HEK 293 and HepG2), followed by $24 \mathrm{~h}$ incubation. The extracts were then applied at the concentration of $100 \mu \mathrm{g} / \mathrm{mL}$ ) for $72 \mathrm{~h}$. Control cells were treated with DMSO at the highest concentration used in test wells $(0.2 \%)$, and cell viability was determined by the MTT colorimetric assay (Biotek Synergy 4), as described previously (Rodrigues et al., 2014). Results were expressed in terms of cellular viability (\%).

\subsection{Statistical analysis}

Results were expressed as mean \pm standard error of the mean (SEM), and experiments were conducted at least in triplicate. Significant differences were assessed by analysis of variance (ANOVA) followed by the Tukey HSD test $(P<0.05)$. All statistical analyses were performed using the XLSTAT statistical package for Microsoft Excel (version 2013, Microsoft Corporation). The IC $_{50}$ values were calculated by the sigmoidal fitting of data using the GraphPad Prism v. 5.0 program.

\section{Results and discussion}

\subsection{Germination and plant growth performance}

Despite the high commercial potential of several halophytes and the need for economically, socially and environmentally viable production systems, research regarding the cultivation of selected species is still limited when compared to glycophytes (Ventura et al., 2015). Moreover, it is known that the plant growth and the biochemical profile of halophytes' obtained biomass can be influenced by agronomic conditions, including the salinity irrigation, and optimized to produce biomass with desired functional properties (Boestfleisch et al., 2014). Thus, this work attempted the greenhouse production of L. algarvense and evaluated the influence of saline irrigation on the growth performance, in vitro antioxidant and chemical properties of the produced plants.

Halophyte seeds' germination is affected by, for example, salinity and temperature (Khan and Gul, 2006), and for several Limonium species, such as L. cossonianum Kuntze, L. tabernense Erben and L. supinum (Girard) Pignatti, highest germinations rates are usually obtained with freshwater treatments (Giménez et al., 2013; Delgado Fernández et al., 2016; Melendo and Giménez, 2019). Therefore, in this work, sea lavender seeds were germinated using freshwater irrigation only. The first seeds germinated after 3 days, and at the end of the 1 st week we observed a germination percentage of $7.4 \%$, which increased to 51.8 and $81.5 \%$ in 2 nd and 3rd weeks, respectively (Fig. 1). In a previous work, the germination rate $(84 \%)$ of $L$. tabernense treated with freshwater and temperatures above $30{ }^{\circ} \mathrm{C}$ (Delgado Fernández et al., 2016), was close to that obtained by L. algarvense. Also, L. supinum seeds also had high germination rates (98\%) when treated with freshwater in all temperature conditions $\left(20 / 10-35 / 25^{\circ} \mathrm{C}\right.$ ) (Melendo and Giménez, 2019). Likewise, $L$. cossonianum exhibited $90 \%$ of germination rate with freshwater soaking (Giménez et al., 2013).

After transplantation and acclimatization, plants were submitted during 14 weeks to different irrigation treatments, including approximately 0 (freshwater), 300 and $600 \mathrm{mM} \mathrm{NaCl}$ of saline aquaculture 




Fig. 1. Percentage of germination of sea lavender (L. algarvense) for three weeks.

wastewater. Afterwards, the above-ground plant organs were harvested and divided into flowers, peduncles and leaves. All plants from all the irrigation conditions survived until the end of the cultivation period. However, plants irrigated with $600 \mathrm{mM} \mathrm{NaCl}$ were not able to produce flower stems and flowers. The moisture and dry matter contents are depicted in Fig. 2. Leaves from freshwater-irrigated plants had the highest moisture content (79.8\%), amongst all treatments. Additionally, leaves' moisture level decreased with increasing salinity, whereas no significant variation was observed in flowers and peduncles (60.5-55.5\% and 60.4-54.1\%, respectively; $P<0.05$ ). Fig. 3 shows the growth performance parameters of sea lavender for each irrigation salinity treatment. The highest number (2.3) and height $(36.4 \mathrm{~cm})$ of the floral stems were obtained in freshwater-irrigated plants, which significantly decreased when plants were irrigated with saline aquaculture wastewater at $300 \mathrm{mM}(P<0.05)$. The same tendency was found in the leaves, concerning its number and surface area (54.7 and $11.6 \mathrm{~cm}^{2}$, respectively; Fig. 3).

Although it is theoretically assumed that halophytes grow better under saline conditions (Panta et al., 2014), there are several reports of different species exhibiting better growth performance under non-saline conditions, similar to our results. For example, this effect was observed on cultivated Inula crithmoides L., Plantago crassifolia Forssk. and Medicago marina L. (Grigore et al., 2012), as well as with Cakile maritima Scop. (Ksouri et al., 2007) and Polygonum maritimum L. (Rodrigues et al., 2019b). These observations may be related to other restrictive aspects besides salinity, as for example, accessibility to light, nutrients, and water, which can influence the interspecific competition (Grigore et al., 2012). Thus, to avoid competition with glycophytes in non-saline habitats, halophytes preferentially colonize saline environments, where they have a competitive advantage due to their salt tolerance (Grigore et al., 2012). In turn, salinity compromises some plant functions, leading to hydric stress, reduced plant biomass, impaired photosynthesis, leaf damage, and nutrients deprivation (Koyro et al., 2008). These problems, coupled with the high toxicity of sodium and chloride ions, may explain the decreased plant growth and consequent reduced leaves number and surface area observed with sea lavenders irrigated with saline water (Ali et al., 2004). The same effects were previously reported with other halophytes, namely Atriplex hortensis L. and C. maritima (Ksouri et al., 2007; Kachout et al., 2009). Similar to our results, salinity also reduced the floral stems and flowers number of C. maritimum (Ventura et al., 2014). However, flowering was stimulated in saline conditions on the halophytes $P$. crassifolia and Suaeda salsa (Grigore et al., 2012; Guo et al., 2018),

Regardless the reduced growth and flowering, sea lavender plants irrigated at $300 \mathrm{mM}$ of $\mathrm{NaCl}$ were able to complete their life cycle (produce flowers and seeds), which indicates that this species can be cultivated under saline irrigation up to that $\mathrm{NaCl}$ level. Additional work is however needed to optimize the cultivation conditions to increase productivity, for example, by optimizing the substrate and nutritional supplementation of the irrigation water (Buhmann et al., 2015).

\subsection{Chemical composition}

The metabolic profile of the sea lavender ethanol extracts was established by LC-ESI-HRMS/MS, and the list of proposed compounds is presented in Table 1. A total of 52 compounds, mainly flavonoids and their glycoside derivatives, were tentatively identified in the flowers, peduncles and leaves, but some were only detected in one specific plant organ, specific irrigation salinity, in wild or cultivated plants.

The flowers had the highest number of compounds (twenty-one) only detected in this organ, which included digalloyl-hexoside (3), hex3-en-1-olxylopyranosyl-(1-6)-glucopyranoside (7), epigallocatechin gallate (9), licoagroside B (10), isorhamnetin-3-O-rutinoside (17), methyl licoagroside B (19), quercetin-tetramethyl ether-dihydroxyethylfructopyranose (20), quercetin-O-hexoside (22), 2'- $C$-methyl myricetin3-rhamnoside-5"-galloyl (23), apigenin-O-glucoside (29), apigenin- $O$ glucuronide (31), luteolin-7-O-glucoside (33), luteolin-7-O-rhamnoside (35), apigenin derivative (37), 4'-methyl eriodictyol-galloyl-rhamnoside (38), eriodictyol (39), naringenin derivative (42), luteolin (44), dihydrokaempferol (45), apigenin (49) and naringenin (50). Seven compounds were only present in the leaves, namely glucosyringic acid (4), eriodyctiol-O-glucoside (11), myricitin-3-O-rutinoside (12), rutin (16), myricetin- $O$-acetyl-hexose (25), quercetin-hexoside derivative (34), myricetin-galloyl-acetyl-deoxyhexose (40). Five molecules were only present in the peduncles, namely galloyl glucose derivative (5), sinapyl alcohol sulfate (6), galloylhexoside derivative (14), $\mathrm{N}$-acetyltryptophan (28) and feruloyltyramine (43).

Phenolic compounds are implicated in several plant-environment interactions (e.g. against herbivory, UV-radiation, pollination) and their

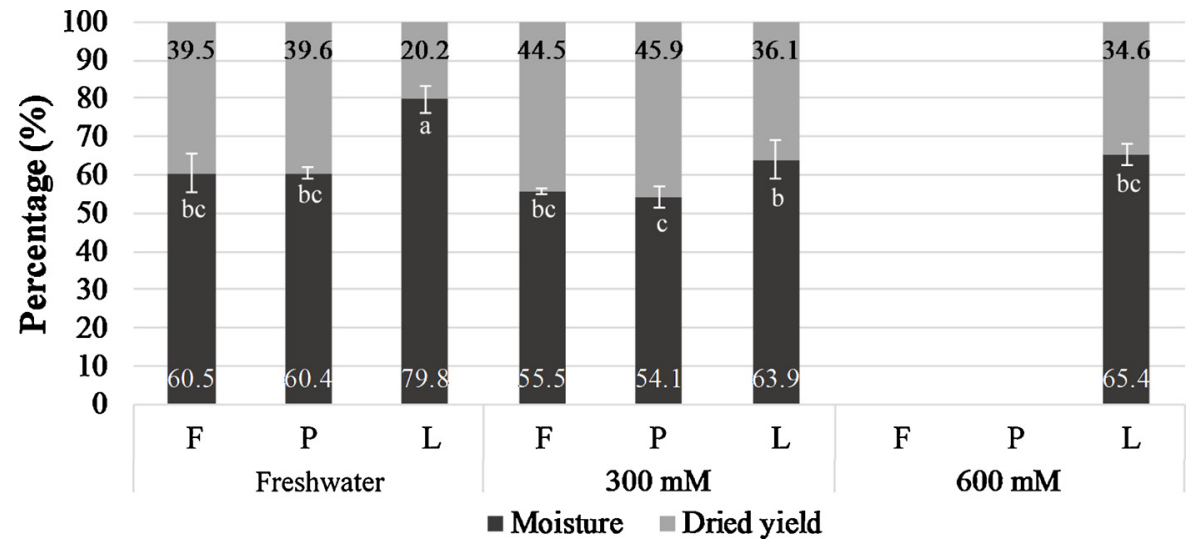

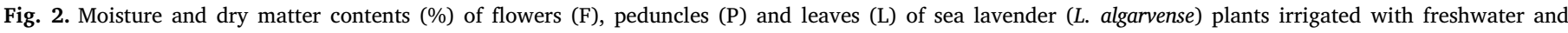

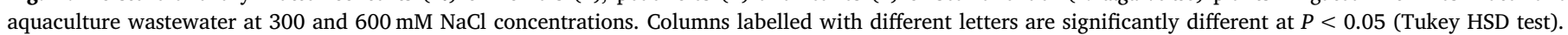




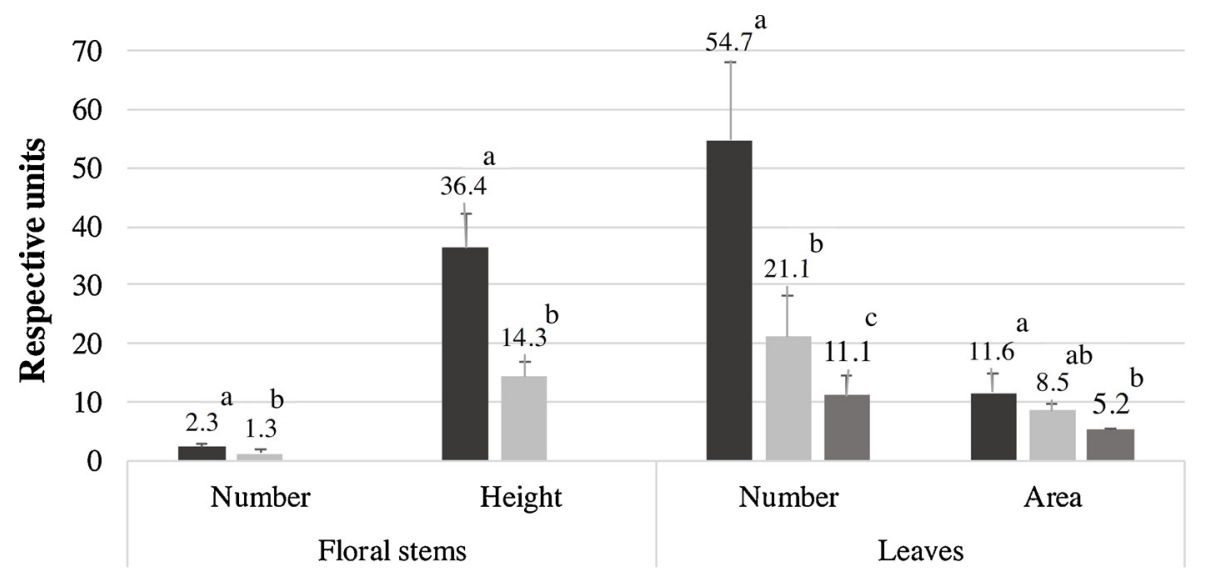

- Freshwater $\quad 300 \mathrm{mM} \quad=600 \mathrm{mM}$

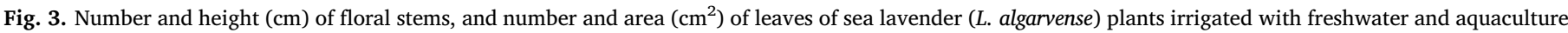

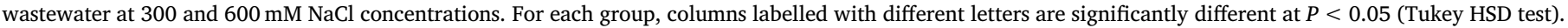

presence on the different plant organs varies according to their biochemical/physiological functions (Pagare et al., 2015). For example, flowers are usually richer in flavonoids, which contribute to pigmentation that is involved in the pollination process (Pichersky and Gang, 2000; Atmani et al., 2009; Iwashina, 2015). The prevalence of flavonoids in the sea lavender flowers is most likely related to these functions.

Amongst all the compounds, a few were only detected in the wild plants' extracts, mainly quercetin (46) and several of its derivatives (16, 34, 47). A higher number of compounds was identified only in the cultivated plants, mostly the flavonoids eriodictyol 39) and some flavonoid glycosides (23, 25, 37). Besides, galloyl glucose (5) and galloyl hexoside (14) derivatives were only present in flowers of freshwaterirrigated plants. Moreover, the relative abundance of several compounds fluctuated with the irrigation salinity. For instance, in the extracts from leaves, the levels of the molecules 1, 18, 30, 32 and 40 decreased with increasing irrigation salinity, reaching the highest content in plants irrigated with freshwater. Conversely, compound 8 exhibited the opposite trend. Regarding the flowers' samples, more compounds had shown a variation with this parameter, for example, the molecules 7, 22, 29, 31, 33, 37, 44, 49 and 51 increased, while 9, 23, 35 and 39 decreased with the increasing irrigation salinity. In turn, compounds 6, 28 and 41 were detected in higher abundance in the peduncles from plants irrigated with freshwater. This variation suggests that some compounds may be produced as a part of a salt-stress resistance mechanism. For example, an increase in the concentration of less hydroxylated flavonoids, such as apigenin (49) and luteolin (44) have been reported to be linked to an enhanced salinity tolerance in some glycophytes, such as endive or rice (El-Shafey and Abdelgawad, 2012; Mekawy et al., 2018). This change for less hydroxylated forms may be associated with an altered activity or/and expression of oxidases and dehydrogenases enzymes (e.g. flavonol synthase and flavonoid 3'-hydroxylase) under stress conditions (Fini et al., 2011; Chapman et al., 2019). For instance, the reduced prevalence of myricetin and its derivatives in the leaves of wild and saline-irrigated plants, coupled with a higher occurrence of more oxidatively stable quercetin and its derivatives found in wild plants, could be related with a more stressful environment, with higher UV-radiation and temperature (in the wild), and increasing salinity of the irrigation solution (in the cultivated plants) (Csepregi and Hideg, 2018).

Overall, just three compounds were previously reported in this species, namely epigallocatechin gallate (9), syringic acid (26) and apigenin (49) in methanol and infusions from flowers of the same species collected from the wild (Rodrigues et al., 2015, 2016, 2019a). However, several of the compounds detected in the present work have already been described in other species of the genus Limonium. Eriodictyol (39) and luteolin (44) were previously detected in ethyl acetate extracts from L. bondueli aerial organs (Benaissa et al., 2013) and from L. bicolor flowers (Chen et al., 2017). The latter species was also described to contain quercetin (46), rutin (16) and quercetin-3-O-rhamnoside (27) (Chen et al., 2017). Medini et al. (2017) reported the occurrence of feruloyltyramine (43), dihydrokaempferol (45) and pinoresinol in L. densiflorum ethanol shoot extract (Medini et al., 2017). In turn, apigenin-O-glucoside (29), luteolin-7-O-glucoside (33) and naringenin (50) were previously detected in ethanol extracts from $L$. insigne inflorescence stems, leaves and roots (Ortuño et al., 2018). Myricetin (36) was already reported in ethanol extracts from aerial parts of L. caspium (Willd) (Gadetskaya et al., 2015).

\subsection{In vitro antioxidant properties}

Several human health problems, including coronary diseases, cancer, age-related degenerative brain disorders, Type 2 diabetes, chronic inflammation, as well as the normal ageing process, can originate or by exacerbated by oxidative stress states (Liguori et al., 2018), which mean the occurrence of an imbalance amongst cellular antioxidant defence systems and the production of reactive oxygen species (ROS) and free radicals. This situation causes the impairment of vital cellular molecules, such as DNA, proteins and lipids, which leads to the development of the diseases mentioned above (Kohen and Nyska, 2002). In this context, antioxidant ingredients can stabilize or deactivate free radicals avoiding and diminishing cellular injury contributing to health maintenance. In this work, the in vitro antioxidant properties of cultivated and wild sea lavender ethanol extracts were assessed using five different methods, namely radical scavenging activity of DPPH and ABTS, metal chelation of iron (ICA) and copper (CCA), and ferric reducing antioxidant power (FRAP). Results are presented in Table 2.

Generally, the wild plants showed the highest antioxidant activity, and flowers had the lowest $\mathrm{IC}_{50}$ value against the DPPH radical $\left(\mathrm{IC}_{50}=123 \mu \mathrm{g} / \mathrm{mL}\right.$ ), whereas the peduncles were the most active on ABTS, CCA and FRAP assays $\left(\mathrm{IC}_{50}=143,320\right.$ and $38 \mu \mathrm{g} / \mathrm{mL}$, respectively). Amongst the cultivated plants, the flowers irrigated with $300 \mathrm{mM} \mathrm{NaCl}$ had the best capacity to scavenge DPPH ( $\mathrm{IC}_{50}=276 \mu \mathrm{g}$ / $\mathrm{mL}$ ), but the flowers from freshwater-irrigated plants had the uppermost RSA towards ABTS, CCA and FRAP ( $\mathrm{IC}_{50}=467,768$ and $117 \mu \mathrm{g}$ / $\mathrm{mL}$, respectively). Concerning the leaf extracts, the FRAP decreased with increasing irrigation salinity, and the best activity was exhibited by the extracts from freshwater-irrigated plants $\left(\mathrm{IC}_{50}=209 \mu \mathrm{g} / \mathrm{mL}\right.$ ). Although a different pattern was found towards DPPH, where extracts from plants irrigated at $300 \mathrm{mM} \mathrm{NaCl}$ had the lowest IC $_{50}$ value at 


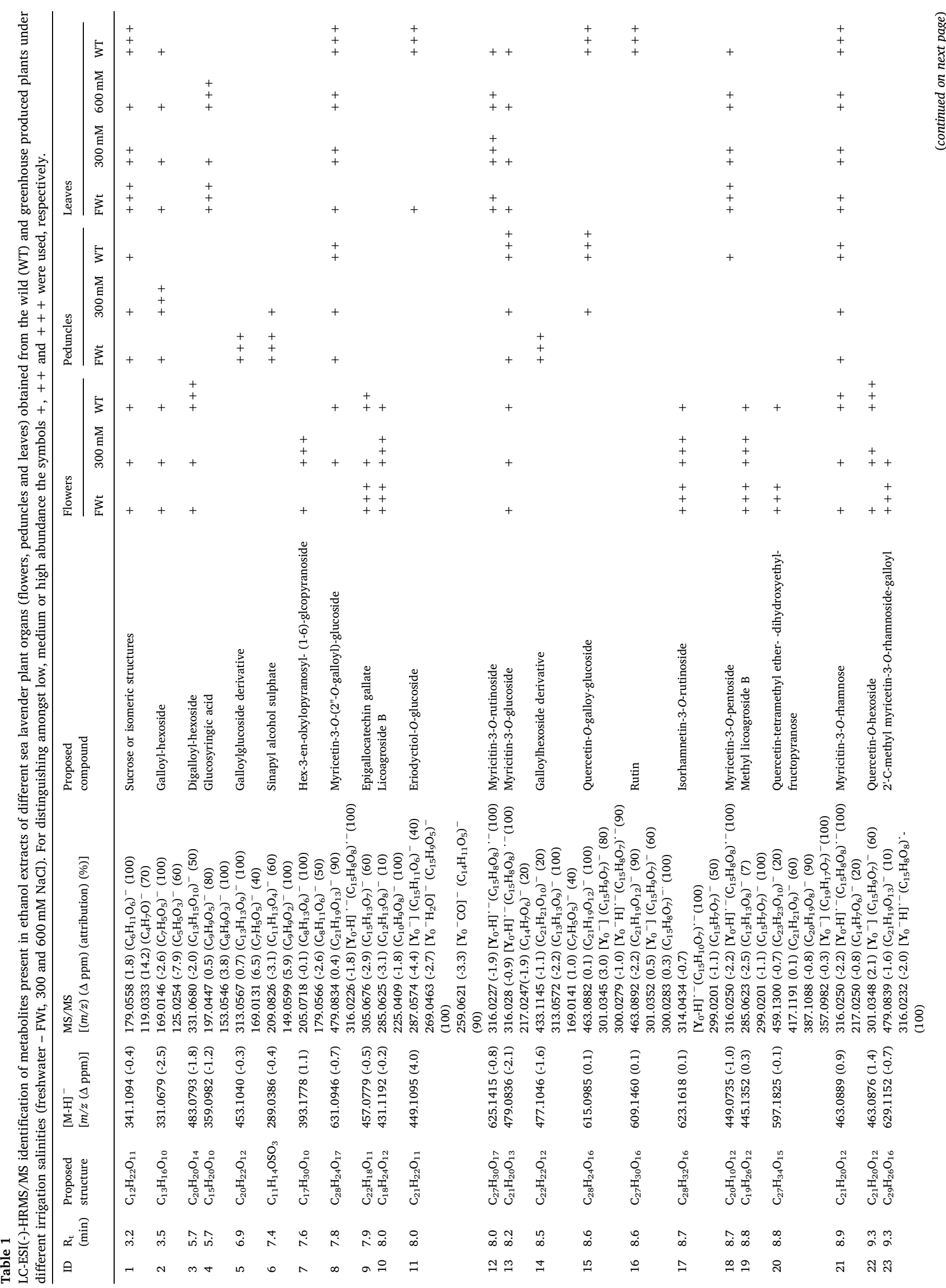




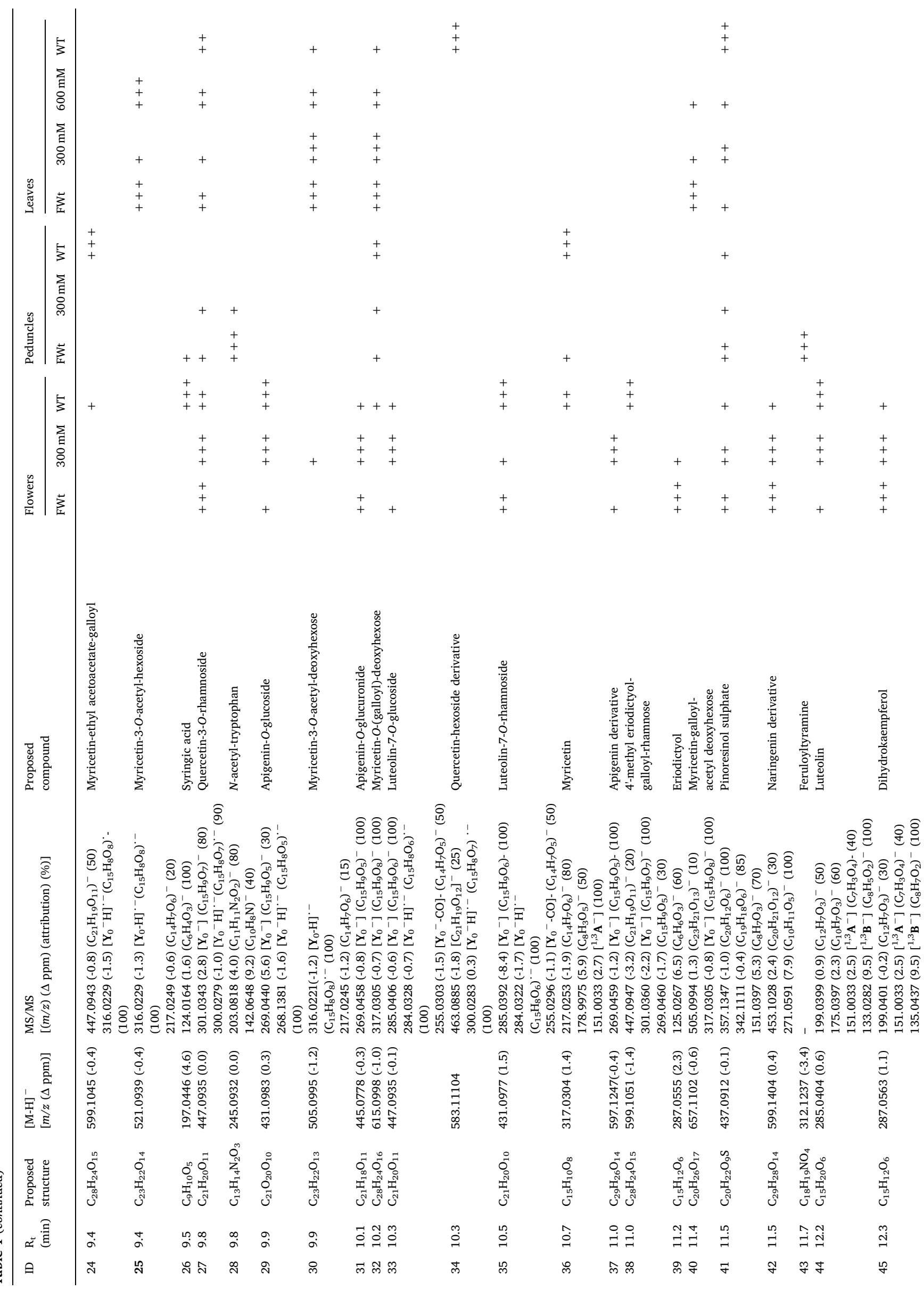


$(647 \mu \mathrm{g} / \mathrm{mL})$, which increased 1.5 times at $600 \mathrm{mM}$-irrigated plants. None of the samples had significant ICA at the concentration of $1 \mathrm{mg}$ / $\mathrm{mL}$.

Flavonoids and their derivatives, as most of the compounds identified in sea lavender extracts, have diverse biological properties (e.g. antiallergenic, antiviral, anti-inflammatory), but their most relevant capacity is as antioxidants (Nijveldt et al., 2001; Kumar and Pandey, 2013). Thus, flavonoid-rich ingredients, such as the sea lavender flower extracts, may neutralize free radicals leading to decreased cellular damage, delaying disease development and improving health (Nijveldt et al., 2001). The highest flavonoids diversity in the flowers may be related to its higher antioxidant properties. Moreover, the highest activity found in the wild plants suggests that salinity may not be the only stress factor that influences the production of antioxidant, such as flavonoids. In fact, the production and accumulation of high levels of antioxidant molecules may result from a combination of several factors, as for example high UV-radiation, temperature, variation between day and night and/or herbivory, as well as salinity (Ramakrishna and Ravishankar, 2011; Yang et al., 2018). Moreover, the accumulation of flavonoids may also be influenced by the developmental stage, species, cultivars and post-harvest processes (Cetinkaya et al., 2017).

Furthermore, the different activity patterns obtained in the various methods may be due to the different mechanisms of reaction of the extracts' compounds with the different oxidizing agents, i.e., the same molecule may react in a distinct way with the different reactive species (Niki and Noguchi, 2000; Dai and Mumper, 2010). In addition, since oxidative stress includes a wide range of reactive species, it is also important to use diverse methods to fully evaluate the antioxidant potential of a sample (Badarinath et al., 2010; Niki, 2010).

Previous work on sea lavender plants collected from the wild described the high in vitro antioxidant potential of methanol extracts from different plant organs, especially from flowers, with significant RSA towards DPPH and ABTS, and also high copper chelating and ferric reducing properties (Rodrigues et al., 2015). Other work focused on the antioxidant properties of infusions and decoction from flowers and suggested that these may have potential as functional beverages (Rodrigues et al., 2016). In this work, the irrigation salinity influenced the antioxidant capacity of obtained extracts, similar to what was already reported for other halophytes. For example, the activity of extracts from Sesuvium portulacastrum (L.) L. was dependent on the plant organ: for instance, leaves and root had increased activity with increasing salinity levels, whereas stems displayed a reduced antioxidant activity (Slama et al., 2015). Also, the same species showed an increased antioxidant activity when irrigated with concentrations up to $400 \mathrm{mM} \mathrm{NaCl}$, followed by a decrease up to $800 \mathrm{mM} \mathrm{NaCl}$ irrigation (Slama et al., 2017). In turn, the antioxidant properties of extracts from six-week-old plants of Bruguiera cylindrica (Linnaeus) Blume, Tripolium pannonicum L. and Lepidium latifolium L. was not influenced by irrigation with saltwater (Boestfleisch et al., 2014). On the contrary, the antioxidant activity of the species Atriplex halimus L. was enhanced with increasing salinity (200-400 $\mathrm{mM} \mathrm{NaCl}$ ) (Bendaly et al., 2016). In the case of $C$. maritima a different pattern was observed according to the different seeds' origin, for example, plants originated from seeds from one location (Tabarka) showed reduced antioxidant activity with higher $\mathrm{NaCl}$ concentrations, whereas those from seeds collected from the other location (Jerba) showed no variation with salinity levels (Ksouri et al., 2007). Another study, comparing the antioxidant properties of C. maritima at two distinct stages (vegetative and flowering), observed a peak in the antioxidant properties on the vegetative period, but during the flowering stage, the activity fluctuated amongst the different soil salinities (Mansour et al., 2018). These facts suggest that the antioxidant properties of produced biomass from halophyte species are influenced by a set of conditions, including not only salinity but also seed origin, stages of growth (vegetative/flowering) and plant organ. A defined pattern cannot be found amongst the reported studies for different halophytes, proposing that these adaptations may be species- 
Table 2

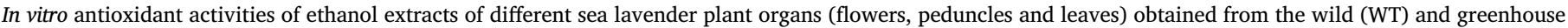
produced plants under different irrigation salinities (freshwater, 300 and $600 \mathrm{mM} \mathrm{NaCl}$ ). Results are expressed as $\mathrm{IC}_{50}$ values $(\mu \mathrm{mg} / \mathrm{mL}$ ).

\begin{tabular}{|c|c|c|c|c|c|c|}
\hline Extract/compound) & Treatment/source & Plant organ & DPPH & ABTS & CCA & FRAP \\
\hline \multirow[t]{10}{*}{ Ethanol } & Freshwater & Flowers & $414 \pm 11^{b}$ & $467 \pm 19^{b}$ & $768 \pm 32^{\mathrm{d}}$ & $117 \pm 1^{\mathrm{c}}$ \\
\hline & & Peduncles & $639 \pm 9^{c}$ & $843 \pm 35^{d}$ & - & $273 \pm 7^{e}$ \\
\hline & & Leaves & - & - & - & $209 \pm 7^{d}$ \\
\hline & $300 \mathrm{mM} \mathrm{NaCl}$ & Flowers & $276 \pm 4^{\mathrm{ab}}$ & $657 \pm 15^{\mathrm{c}}$ & - & $269 \pm 9^{e}$ \\
\hline & & Peduncles & $692 \pm 11^{\mathrm{c}}$ & $898 \pm 30^{d}$ & - & $205 \pm 5^{d}$ \\
\hline & & Leaves & $647 \pm 25^{c}$ & - & - & $325 \pm 17^{\mathrm{f}}$ \\
\hline & $600 \mathrm{mM} \mathrm{NaCl}$ & Leaves & $946 \pm 13$ & - & - & $376 \pm 9^{g}$ \\
\hline & Wild & Flowers & $123 \pm 3^{\mathrm{a}}$ & $199 \pm 16^{\mathrm{a}}$ & $348 \pm 6^{b}$ & $81 \pm 6^{b c}$ \\
\hline & & Peduncles & $373 \pm 6^{\mathrm{b}}$ & $143 \pm 4^{\mathrm{a}}$ & $320 \pm 2^{b}$ & $38 \pm 3^{\mathrm{a}}$ \\
\hline & & Leaves & $149 \pm 5^{a}$ & $625 \pm 62^{\mathrm{c}}$ & $627 \pm 7^{c}$ & $74 \pm 10^{\mathrm{ab}}$ \\
\hline Positive control* & & & $111 \pm 9^{a}$ & $142 \pm 11^{\mathrm{a}}$ & $171 \pm 9^{a}$ & - \\
\hline
\end{tabular}

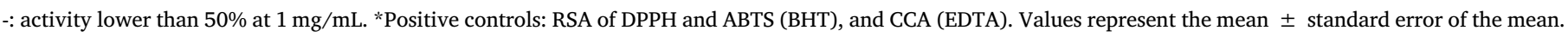

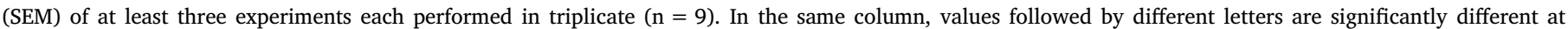
$P<0.05$ (Tukey HSD test).

specific.

\subsection{Toxicological evaluation}

Natural products are generally acknowledged to be safer than the synthetic ones (Karimi et al., 2015). However, plants can be intrinsically toxic due to their chemical composition, (Nasri and Shirzad, 2013) and therefore, it is of utmost importance to ensure their safety for potential consumers. The toxicity of botanical ingredients is usually determined by their cytotoxic effects on mammalian cell lines as it is suggested to correlate in a positive way to in vivo models (Carballo et al., 2002; Parra et al., 2001; Blazka and Hayes, 2001). Following this, the sea lavender ethanol extracts were evaluated for their in vitro cytotoxicity on three mammalian cell lines: murine RAW 264.7 macrophages, human embryonic kidney (HEK) 293, and human hepatocellular carcinoma HepG2 cells (Fig. 4). Samples allowing cellular viabilities higher than $80 \%$ were considered non-toxic (Rodrigues et al., 2014, 2016).

All the extracts had no toxicity against HEK 293 and HepG2 cell lines, with viabilities generally higher than 100\%. Regarding HEK 293 cells, extracts from flowers of freshwater-irrigated plants had the highest values of cell viability (142\%). Similarly, several samples increased HepG2 cells viability over $150 \%$, such as the flowers extract from plants irrigated with $300 \mathrm{mM} \mathrm{NaCl}$ and from those collected from the wild (185 and 176\%, respectively). However, a few extracts reduced the viability of RAW cells, namely the wild leaves and peduncles (67.4 and $74.3 \%$, respectively), leaves of plants irrigated with $300 \mathrm{mM}$ aquaculture wastewater (75.4\%) and peduncles of freshwater-irrigated plants (78.2\%). The remaining samples were considered non-toxic towards RAW 264.7 macrophages.

The increased cellular viability observed after the application of sea lavender extracts could have two different explanations. First, it is important to keep in mind that the MTT assay is a colorimetric assay that measures the activity of mitochondrial NAD(P)H-dependent cellular oxidoreductase enzyme to reduced MTT (Aslantürk, 2017). Therefore, an increase in cellular viability may be the result of increased enzymatic activity or higher cellular proliferation.

Moreover, and despite being described with anti-tumour effects, flavonoids have shown low or nil-toxicity towards non tumoral cells (Nijveldt et al., 2001), and in fact several flavonoids, such as apigenin, quercetin, naringenin and rutin (present in sea lavender extracts) have been reported with hepatoprotective effects, i.e., protect against induced hepatotoxicity in HepG2 cells, and also with liver regenerative properties (Tapas et al., 2008; Kumar and Pandey, 2013). This may also explain the increased cellular viability resulting from the application of sea lavender extracts. Besides, the reduced cell viability induced by the wild plants rather than greenhouse produced ones, can be associated
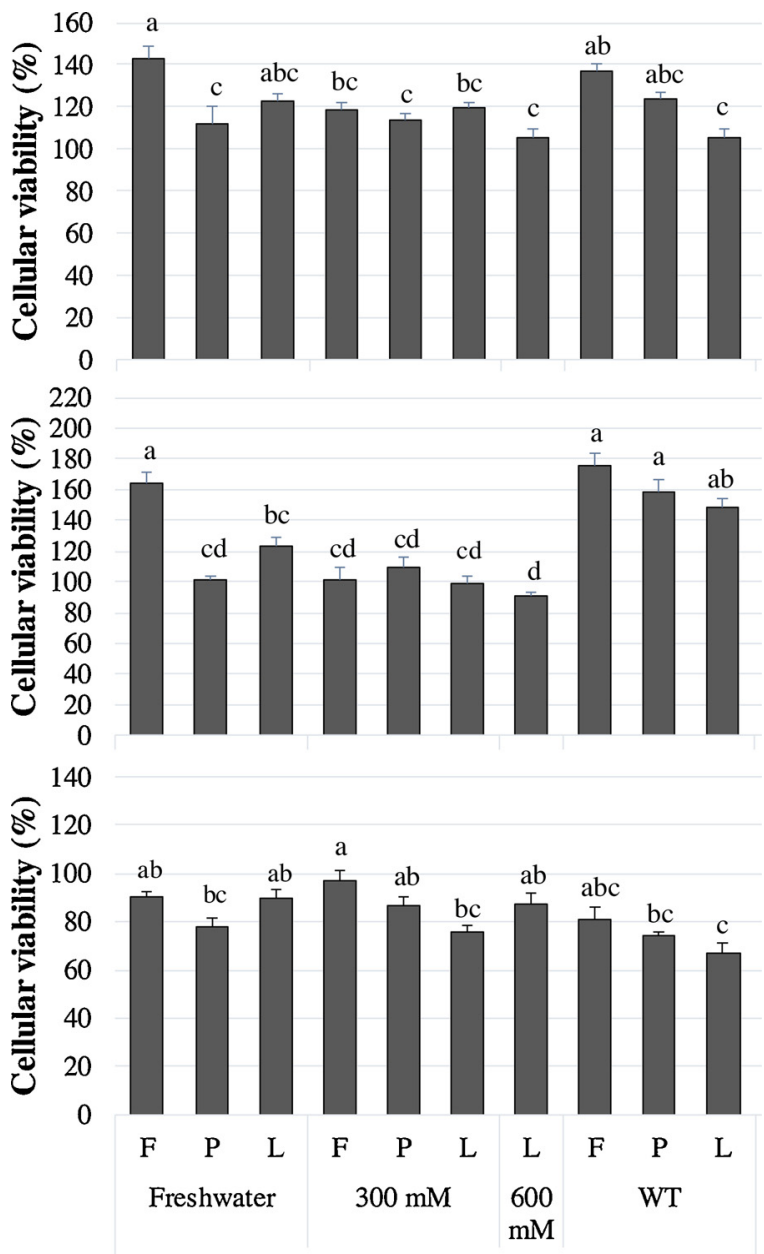

Ethanol

Fig. 4. Cytotoxicity of ethanol extracts of sea lavender (L. algarvense) organs (F - flowers; P - peduncles; and L - leaves) from plants irrigated with freshwater and two concentrations of aquaculture wastewater (300 and $600 \mathrm{mM} \mathrm{NaCl}$ ), and plants collected from the wild (WT) on HEK 293 (A), HepG2 (B), and RAW 264.7 (C) cell lines. Values represent the mean \pm standard error of the mean (SEM) of at least three experiments performed in triplicate $(n=9)$. Columns marked by different letters are significantly different according to the Tukey HSD test $(P<0.05)$.

with the occurrence of some toxic compounds (e.g. alkaloids), which are usually synthesized by wild plants for protection against herbivores (Stamp, 2008). 
Infusions and decoctions made from sea lavender flowers were identified previously as a potential antioxidant and anti-inflammatory functional beverages, and the toxicological assessment of these formulations was also reported against mammalian cell lines (Rodrigues et al., 2016). Similar to the present results, all samples were non-toxic at $100 \mu \mathrm{g} / \mathrm{mL}$, and some increased HepG2 and microglial (N9) cells viability above $100 \%$ (Rodrigues et al., 2016). Since the in vitro toxicity against mammalian cell lines is positively correlated with in vivo toxicity on mice (Garle et al., 1994; Di Nunzio et al., 2017), the results of our study indicate that extracts from the cultivated sea lavender may be considered as safe for application as nutraceutical ingredients. Nevertheless, additional experiments are needed to confirm these preliminary tests.

\section{Conclusions}

In this study, we report for the first time the cultivation of sea lavender in greenhouse conditions under irrigation with saline aquaculture wastewater (at two $\mathrm{NaCl}$ levels), and the influence of that salinity on plant growth, and on the in vitro antioxidant, toxicological and chemical properties of ethanol extracts from aerial organs of produced sea lavenders, compared to those from wild plants. Overall, the obtained results suggest that:

1) Sea lavender plants can be successfully cultivated in greenhouse conditions and irrigated with freshwater and with irrigation salinity up to $300 \mathrm{mM} \mathrm{NaCl}$. The percentage of germination after 3 weeks was $81 \%$ and sea lavender plants irrigated with freshwater and at $300 \mathrm{mM} \mathrm{NaCl}$ were able to complete their life cycle (produce flowers and seeds).

2) The irrigation salinity influences plant performance, chemical composition and in vitro antioxidants properties of produced sea lavender plants. Freshwater irrigated plants exhibited better growth performance, plants irrigated with $300 \mathrm{mM} \mathrm{NaCl}$ were able to complete the life cycle while those irrigated with $600 \mathrm{mM} \mathrm{NaCl}$ were not able to produce flower stems and flowers; the irrigation salinity decreased plant growth, including the number of flowers and leaves. The in vitro antioxidant properties and the chemical composition were maintained under saline and non-saline irrigation.

3) Cultivated plants retain the in vitro antioxidant properties and chemical components of wild plants. Although extracts from wild plants had generally a higher RSA on the DPPH and ABTS radicals, copper chelating and ferric reducing activities than those from cultivated ones, a significant antioxidant capacity was still observed in extracts from cultivated plants. Flavonoids were the main compounds present in the extracts and their presence varied within the source of biomass (wild/cultivated). However, cultivated plants were still rich in bioactive molecules.

Therefore, sea lavender could be candidate for commercial production in saline conditions, for example in IMTA system using diluted aquaculture wastewater, or in other systems using brackish water for irrigation, to be used as a source of bioactive ingredients.

The authors whose names are listed immediately below certify that they have NO affiliations with or involvement in any organization or entity with any financial interest (such as honoraria; educational grants; participation in speakers' bureaus; membership, employment, consultancies, stock ownership, or other equity interest; and expert testimony or patent-licensing arrangements), or non-financial interest (such as personal or professional relationships, affiliations, knowledge or beliefs) in the subject matter or materials discussed in this manuscript.

\section{Declaration of Competing Interest}

The authors whose names are listed immediately below certify that they have NO affiliations with or involvement in any organization or entity with any financial interest (such as honoraria; educational grants; participation in speakers' bureaus; membership, employment, consultancies, stock ownership, or other equity interest; and expert testimony or patent-licensing arrangements), or non-financial interest (such as personal or professional relationships, affiliations, knowledge or beliefs) in the subject matter or materials discussed in this manuscript.

Author names: Maria João Rodrigues, Ivo Monteiro, Viana Castañeda-Loaiza, Chloé Placines, M. Conceição Oliveira, Catarina Reis, Ana D. Caperta, Florbela Soares, Pedro Pousão-Ferreira, Catarina Pereira and Luísa Custódio.

\section{Acknowledgements}

Work supported by the Foundation for Science and Technology (FCT) and the Portuguese National Budget (CCMAR/Multi/04326/2019 project), GreenVet project (ALG-01-0145-FEDER-028876), XtremeAquaCrops (FA-05-2017-028), (Lisboa-01-0145-FEDER-022125RNEM-IST) and ID/QUI/00100/201. Maria João Rodrigues acknowledges FCT for the PhD grant SFRH/BD/116604/2016. Luísa Custódio was supported by FCT Scientific Employment Stimulus (CEECIND/ 00425/2017).

\section{Appendix A. Supplementary data}

Supplementary material related to this article can be found, in the online version, at doi:https://doi.org/10.1016/j.indcrop.2019.111930.

\section{References}

Ali, Y., Aslam, Z., Ashraf, M.Y., Tahir, J.R., 2004. Effect of salinity on chlorophyll concentration, leaf area, yield and yield components of rice genotypes grown under saline environment. Int. J. Environ. Sci. Technol. 1, 221-225.

Aslantürk, O.S., 2017. In vitro cytotoxicity and cell viability assays: principles, advantages, and disadvantages. In: Larramendy, Marcelo L., Soloneski, Sonia (Eds.), Genotoxicity - A PrediCtable Risk to Our Actual World. IntechOpen.

Atmani, D., Chaher, N., Berboucha, M., Ayouni, K., Lounis, H., Boudaoud, H., Debbache, N., Atmani, D., 2009. Antioxidant capacity and phenol content of selected Algerian medicinal plants. Food Chem. 112, 303-309.

Badarinath, A.V., Rao, K.M., Chetty, C.M.S., Ramkanth, S., Rajan, T.V.S., Gnanaprakash, K., 2010. A review on in-vitro antioxidant methods: comparisions, correlations and considerations. IJPRIF 2, 1276-1285.

Benaissa, O., Amrani, A., Bicha, S., Zama, D., Benayache, F., Marchioni, E., Samir, B., 2013. Free radical scavenging action of phenolic compounds from Limonium bondueli (Plumbaginaceae). Pharm. Lett. 5, 234-240.

Bendaly, A., Messedi, D., Smaoui, A., Ksouri, R., Bouchereau, A., Abdelly, C., 2016. Physiological and leaf metabolome changes in the xerohalophyte species Atriplex halimus induced by salinity. Plant Physiol. Biochem. 103, 208-218.

Biotona, 2019. https://www.biotona.be/en/product/seabuckthorn/. (Accessed in 16.04. 2019).

Blazka, M.E., Hayes, W., 2001. Acute toxicity and eye irritancy. Principles and Methods of Toxicology, 5th ed. CRC Press, Taylor and Francis Group, New York, pp. 1131-1141.

Boestfleisch, C., Wagenseil, B.N., Buhmann, A.K., Seal, C.E., MerrettWade, E., Muscolo, A., Papenbrock, J., 2014. Manipulating the antioxidant capacity of halophytes to increase their cultural and economic value through saline cultivation. AoB Plants 6, $1-16$.

Buhmann, A., Waller, U., Wecker, B., Papenbrock, J., 2015. Optimization of culturing conditions and selection of species for the use of halophytes as biofilter for nutrientrich saline water. Agric. Water Manag. 149, 102-114.

Carballo, J.L., Hernández-Inda, Z.L., Pérez, P., García-Grávalos, M.D., 2002. A comparison between two brine shrimp assays to detect in vitro cytotoxicity in marine natural products. BMC Biotechnol. 2, 17.

Cetinkaya, H., Kulak, M., Karaman, M., Karaman, H.S., Kocer, F., 2017. Flavonoid accumulation behavior in response to the abiotic stress: can a uniform mechanism be illustrated for all plants? In: Justino, Goncalo C. (Ed.), Flavonoids - From Biosynthesis to Human Health. IntechOpen.

Chapman, J.M., Muhlemann, J.K., Gayomba, S.R., Muday, G.K., 2019. RBOH-dependent ROS synthesis and ROS scavenging by plant specialized metabolites to modulate plant development and stress responses. Chem. Res. Toxicol. 32, 370-396.

Chen, J., Teng, J., Ma, L., Tong, H., Ren, B., Wang, L., Li, W., 2017. Flavonoids isolated from the flowers of Limonium bicolor and their in vitro antitumor evaluation. Pharmacogn. Mag. 13, 222-225.

Csepregi, K., Hideg, É., 2018. Phenolic compound diversity explored in the context of photo-oxidative stress protection. Phytochem. Anal. 29, 129-136.

Custódio, M., Villasante, S., Cremades, J., Calado, R., Lillebø, A.I., 2017. Unravelling the 
potential of halophytes for marine integrated multi-trophic aquaculture (IMTA) - a perspective on performance, opportunities and challenges. Aquacult. Environ. Interact. 9, 445-460.

Dai, J., Mumper, R.J., 2010. Plant phenolics: extraction, analysis and their antioxidant and anticancer properties. Molecules 15, 7313-7352.

Delgado Fernández, I.C., Giménez Luque, E., Gómez Mercado, F., Pedrosa, W., 2016. Influence of temperature and salinity on the germination of Limonium tabernense Erben from Tabernas Desert (Almería, SE Spain). Flora 218, 68-74.

Di Nunzio, M., Valli, V., Tomás-Cobos, L., Tomás-Chisbert, T., Murgui-Bosch, L., Danesi, F., Bordoni, A., 2017. Is cytotoxicity a determinant of the different in vitro and in vivo effects of bioactives? BMC Complement. Altern. Med. 17, 453.

El-Shafey, N.M., AbdElgawad, H., 2012. Luteolin, a bioactive flavone compound extracted from Cichorium endivia L. Subsp. Divaricatum alleviates the harmful effect of salinity on maize. Acta Physiol. Plant. 34, 2165-2177.

Fini, A., Brunetti, C., Di Ferdinando, M., Ferrini, F., Tattini, M., 2011. Stress-induced flavonoid biosynthesis and the antioxidant machinery of plants. Plant Signal. Behav. 6, 709-711.

Flowers, T.J., Colmer, T.D., 2008. Salinity tolerance in halophytes. New Phytol. 179, 945-963.

Flowers, T.J., Galal, H.K., Bromham, L., 2010. Evolution of halophytes: multiple origins of salt tolerance in land plants. Funct. Plant Biol. 37, 604-612.

Gadetskaya, A.V., Tarawneh, A.H., Zhusupova, G.E., Gemejiyeva, N.G., Cantrell, C.L., Cutler, S.J., Ross, S.A., 2015. Sulfated phenolic compounds from Limonium caspium: isolation, structural elucidation, and biological evaluation. Fitoterapia 104, 80-85.

Garle, M., Fentem, J., Fry, J., 1994. In vitro cytotoxicity tests for the prediction of acute toxicity in vivo. Toxicol. In Vitro 8, 1303-1312.

Giménez Luque, E., Delgado Fernández, I.C., Gómez Mercado, F., 2013. Effect of salinity and temperature on seed germination in Limonium cossonianum. Botany 91, 12-16.

Grand View Research, 2017. Nutraceuticals Market Analysis By Product (Dietary Supplements, Functional Food, Functional Beverage), By Region (North America, Asia Pacific, Europe, CSA, MEA), And Segment Forecasts, 2018-2025.

Grigore, M.N., Villanueva, M., Bosnau, M., Vicente, O., 2012. Do halophytes really require salts for their growth and development? An experimental aproach. Not. Sci. Biol. 4, 23-29.

Guo, J., Li, Y., Han, G., Song, J., Wang, B., 2018. NaCl markedly improved the reproductive capacity of the euhalophyte Suaeda salsa. Funct. Plant Biol. 45, 350-361.

Iwashina, T., 2015. Contribution to flower colors of flavonoids including anthocyanins: a review. Nat. Prod. Commun. 10, 529-544.

Kachout, S., Mansoura, A.B., Jaffel, K., Leclerc, J., Rejeb, M.N., Ouerghi, Z., 2009. The effect of salinity on the growth of the halophyte Atriplex hortensis (Chenopodiaceae). Appl. Ecol. Environ. Res. 7, 319-332.

Karimi, A., Majlesi, M., Rafieian-Kopaei, M., 2015. Herbal versus synthetic drugs; beliefs and facts. J. Nephropharmacol. 4, 27-30.

Khan, M.A., Gul, B., 2006. Halophyte seed germination. In: Khan, M.A., Weber, D.J. (Eds.), Ecophysiology of High Salinity Tolerant Plants. Springer Verlag, Netherlands, pp. 11-30.

Kohen, R., Nyska, A., 2002. Oxidation of biological systems: oxidative stress phenomena, antioxidants, redox reactions, and methods for their quantification. Toxicol. Pathol. $30,620-650$.

Koyro, H.W., Geißler, N., Hussin, S., Debez, A., Huchzermeyer, B., 2008. Strategies of halophytes to survive in a salty environment. In: Khan, Nafees, Gill, Sarvajeet Singh (Eds.), Abiotic Stress and Plant Responses. I K International, New Delhi, pp. 79-101.

Koyro, H.W., Huchzermeyer, B., 2004. Ecophysiological needs of the potential biomass crop Spartina townsendii GROV. Trop. Ecol. 45, 123-139.

Ksouri, R., Ksouri, W.M., Jallali, I., Debez, A., Magné, C., Hiroko, I., Abdelly, C., 2012. Medicinal halophytes: potent source of health promoting biomolecules with medical, nutraceutical and food applications. Crit. Rev. Biotechnol. 32, 289-326.

Ksouri, R., Megdiche, W., Debez, A., Falleh, H., Grignon, C., Abdelly, C., 2007. Salinity effects on polyphenol content and antioxidant activities in leaves of the halophyte Cakile maritima. Plant Physiol. Biochem. 45, 244-249.

Kumar, K., Pandey, A.K., 2013. Chemistry and biological activities of flavonoids: an overview, Sci. World J. 162750, 16.

Liguori, I., Russo, G., Curcio, F., Bulli, G., Aran, L., Della-Morte, D., Gargiulo, G., Testa, G., Cacciatore, F., Bonaduce, D., Abete, P., 2018. Oxidative stress, aging, and diseases. Clin. Interv. Aging 13, 757-772.

Mansour, R.B., Dakhlaouia, S., Msahli, W., Ksouri, R., Ksouri, M.W., 2018. Differential responses of Cakile maritima at two development stages to salinity: changes on phenolic metabolites and related enzymes and antioxidant activity. Med. Chem. (Los Angeles) 8, 100.

Medini, F., Bourgou, S., Lalancette, K., Snoussi, M., Mkadmini, K., Cotéc, I., Abdelly, C., Legault, J., Ksouri, R., 2017. Phytochemical analysis, antioxidant, anti-inflammatory, and anticancer activities of the halophyte Limonium densiflorum extracts on human cell lines and murine macrophages. S. Afr. J. Bot. 99, 158-164.

Mekawy, A.M.M., Abdelaziz, M.N., Ueda, A., 2018. Apigenin pretreatment enhances growth and salinity tolerance of rice seedlings. Plant Physiol. Biochem. 130, 94-104.

Melendo, M., Giménez, E., 2019. Seed germination responses to salinity and temperature in Limonium supinum (Plumbaginaceae), an endemic halophyte from Iberian Peninsula. Plant Biosyst. 153, 257-263.

Miroddi, M., Mannucci, C., Mancari, F., Navarra, M., Calapai, G., 2013. Research and development for botanical products in medicinals and food supplements market. J. Evid. Based Complement. Altern. Med. 2013, 649720.

Nasri, H., Baradaran, A., Shirzad, H., Rafieian-Kopaei, M., 2014. New concepts in nutraceuticals as alternative for pharmaceuticals. Int. J. Prev. Med. 5, 1487-1499.
Nasri, H., Shirzad, H., 2013. Toxicity and safety of medicinal plants. J. Herbmed Pharmacol. 2, 21-22.

Nicoletti, M., 2012. Nutraceuticals and botanicals: overview and perspectives. Int. J. Food Sci. Nutr. 63, 2-6.

Nijveldt, R.J., van Nood, E., van Hoorn, D.E.C., Boelens, P.G., van Norren, K., van Leeuwen, P.A.M., 2001. Flavonoids: a review of probable mechanisms of action and potential applications. Am. J. Clin. Nutr. 74, 418-425.

Niki, E., 2010. Assessment of Antioxidant Capacity in vitro and in vivo. Free Radic. Biol. Med. 49, 503-515.

Noguchi, N., Niki, E., 2000. Phenolic antioxidants: a rationale for design and evaluation of novel antioxidant drug for aterosclerosis. Free Radic. Biol. Med. 28, 1538-1546.

Ortuño, A., Díaz, L., Pérez, I., Sánchez, F., Del Río, J., 2018. Biological active compounds from Limonium insigne and alternative methods for its micropropagation. Sci. Hortic. 230, 78-85.

Pagare, S., Bhatia, M., Tripathi, N., Pagare, S., Bansal, Y.K., 2015. Secondary metabolites of plants and their role: overview. Curr. Trends Biotechnol. Pharm. 9, 293-304.

Panche, A.N., Diwan, A.D., Chandra, S.R., 2016. Flavonoids: an overview. J. Nutr. Sci. 5, $1-15$.

Panta, S., Flowers, T., Lane, P., Doyle, R., Haros, G., Shabala, S., 2014. Halophyte agriculture: success stories. Environ. Exp. Bot. 107, 71-83.

Parra, A.L., Yhebra, S.R., Sardiñas, G.I., Buela, I.L., 2001. Comparative study of the assay of Artemia salina L. and the estimate of the medium lethal dose (LD50 value) in mice, to determine oral acute toxicity of plant extracts. Phytomedicine 8, 395-400.

Phytomer, 2019. https://www.phytomerusa.com/marine-active-ingredients. (Accessed in 16.04.2019).

Pichersky, E., Gang, D.R., 2000. Genetics and biochemistry of secondary metabolites in plants: an evolutionary perspective. Trends Plant Sci. 5, 439-445.

Pipingrock, 2019. https://www.pipingrock.com/sea-buckthorn-oil. (Accessed in 16.04. 2019).

QuinoaPortuguesa, 2019. https://www.quinoaportuguesa.com/. (Accessed in 16.04. 2019).

Ramakrishna, A., Ravishankar, G.A., 2011. Influence of abiotic stress signals on secondary metabolites in plants. Plant Signal. Behav. 6, 1720-1731.

Riafresh, 2019. http://www.riafresh.com/index.php/pt/portfolio. (Accessed in 16.04. 2019).

Rodrigues, M.J., Neves, V., Martins, A., Rauter, A.P., Neng, N.R., Nogueira, J.M.F., Varela, J., Barreira, L., Custódio, L., 2016. In vitro antioxidant and anti-inflammatory properties of Limonium algarvense flowers' infusions and decoctions: a comparison with green tea (Camellia sinensis). Food Chem. 200, 322-329.

Rodrigues, M.J., Oliveira, M., Neves, V., Ovelheiro, A., Pereira, C., Neng, N.R., Nogueira, J.M.F., Varela, J., Barreira, L., Custódio, L., 2019a. Coupling sea lavender (Limonium algarvense Erben) and green tea (Camellia sinensis (L.) Kuntze) to produce an innovative herbal beverage with enhanced enzymatic inhibitory properties. S. Afr. J. Bot. 120, 87-94.

Rodrigues, M.J., Gangadhar, K.N., Vizetto-Duarte, C., Wubshet, S.G., Nyberg, N.T., Barreira, L., Varela, J., Custódio, L., 2014. Maritime halophyte species from southern Portugal as sources of bioactive molecules. Mar. Drugs 12, 2228-2244.

Rodrigues, M.J., Monteiro, I., Placines, C., Castañeda-Loaiza, V., Ślusarczyk, S., Matkowski, A., Pereira, C., Pousão, P., Custódio, L., 2019b. The irrigation salinity and harvesting affect the growth, chemical profile and biological activities of Polygonum maritimum L. Ind. Crops Prod. 139, 111510.

Rodrigues, M.J., Soszynski, A., Martins, A., Rauter, A.P., Neng, N.R., Nogueira, J.M.F., Varela, J., Barreira, L., Custódio, L., 2015. Unravelling the antioxidant potential and the phenolic composition of different anatomical organs of the marine halophyte Limonium algarvense. Ind. Crop. Prod. 77, 315-322.

Seppic, 2019. https://www.seppic.com/celtosome-crithmum-maritimum-st. (Accessed in 16.04.2019)

Slama, I., M’Rabet, R., Ksouri, R., Talbi, O., Debez, A., Abdelly, C., 2015. Water deficit stress applied only or combined with salinity affects physiological parameters and antioxidant capacity in Sesuvium portulacastrum. Flora Morphol. Distrib. Funct. Ecol. Plants 213, 69-76.

Slama, I., M'Rabet, R., Ksouri, R., Talbi, O., Debez, A., Abdelly, C., 2017. Effects of salt treatment on growth, lipid membrane peroxidation, polyphenol content, and antioxidant activities in leaves of Sesuvium portulacastrum L. Arid Land. Arid L. Res. Manag. 31, 404-417.

Stamp, N., 2008. Plant defense. In: Jørgensen, Sven Erik, Fath, Brian D. (Eds.), Encyclopedia of Ecology. Academic Press, pp. 2794-2797.

Tapas, A.R., Sakarkar, D.M., Kakde, R.B., 2008. Flavonoids as nutraceuticals: a review. Trop. J. Pharm. Res. 7, 1089-1099.

Troell, M., Joyce, A., Chopin, T., Neori, A., Buschmann, A.H., Fang, J.G., 2009. Ecological engineering in aquaculture - Potential for integrated multi-trophic aquaculture (IMTA) in marine offshore systems. Aquaculture 297, 1-9.

Ventura, Y., Eshel, A., Pasternak, D., Sagi, M., 2015. The development of halophyte-based agriculture: past and present. Ann. Bot. 115, 529-540.

Ventura, Y., Myrzabayeva, M., Alikulov, Z., Omarov, R., Khozin-Goldberg, I., Sagi, M., 2014. Effects of salinity on flowering, morphology, biomass accumulation and leaf metabolites in an edible halophyte. AoB Plants 6, 55-64.

Waller, U., Buhmann, K.A., Ernst, A., Hanke, V., Kulakowski, A., Wecker, B., Orellana, J., Papenbrock, J., 2015. Integrated multi-trophic aquaculture in a zero-exchange recirculation aquaculture system for marine fish and hydroponic halophyte production. Aquac. Int. 23, 1473-1489.

Yang, L., Wen, K.S., Ruan, X., Zhao, Y.X., Wei, F., Wang, Q., 2018. Response of plant secondary metabolites to environmental factors. Molecules 23, 762. 